\title{
Transforming the Transcript to Reflect the Whole Scholar: Legitimizing Pedagogical Training for Graduate Student I nstructors
}

\author{
Josh Iorio, PhD \\ Post-Doctoral Research Fellow, Network Dynamics Lab \\ Columbia University \\ Mark Lowry Decker, MSSW \\ Doctoral Candidate, Educational Psychology \\ University of Texas at Austin
}

Although universities acknowledge that teacher training is critical for ensuring quality undergraduate education, research has repeatedly demonstrated that universities typically do an inadequate job of preparing graduate students for their instructor role. In this paper, we show that both graduate students and universities find the pedagogical development of graduate students to be a valid endeavor, and while graduate students strive to legitimize their own pedagogical development, universities must more fully and officially engage in the process. We conclude with a short list of recommendations for universities to consider toward the goal of legitimizing graduate student pedagogical development.

Research has suggested that graduate programs do not adequately prepare graduate students for the multifaceted roles required of faculty (Golde \& Dore, 2001; Smallwood, 2001). For a growing majority of graduate students seeking positions in higher education, one such role is that of teacher (Benassi \& Fernald, 1993; Graft \& Lambert, 1996). Research also suggests that few graduate programs adequately prepare graduate students to become effective teachers (Darling \& Dewey, 1990; Lowman \& Mathie, 1993; Meyers \& Prieto, 2000; Prieto \& Meyers, 1999), leaving them with ethical dilemmas as they wonder whether they are qualified to teach the courses they are assigned (Branstetter \& Handelsman, 2000; Kuther, 2003). Graduate students must decide whether to accept funding offered for teaching positions (Kuther, 2002) even if they lack adequate training in best teaching

So, the task for those who support TA's is not to deemphasize research or other aspects of scholarship but rather to ensure that teaching and teacher training are appropriately appreciated as essential for TA's to develop the selfefficacy, socialization, and competencies requisite for success in the classroom.

practices (Cahn, 1994). For many graduate students, financial need often trumps their lack of confidence in their preparation for the classroom.

A graduate student's initial teaching experience is often as a teaching assistant (TA). At some institutions, TA's perform basic administrative tasks, such as making copies, checking attendance, and distributing class materials. At others, TAs are given robust pedagogical responsibilities, such as designing course curricula, leading discussions, and developing assessments of student learning. Our focus in this article is on TAs with this last responsibility.

Because "teaching assistantships are the foundation of faculty development" (Prieto, 2002, p. 2), it is critical to address the complete development of graduate students by socializing them, as Austin and McDaniels (2006a) explain, with "experiences that help students develop as researchers, teachers, service providers and institutional citizens" (p. 444). Austin and McDaniels (2006b) refer to four domains of scholarly work: (1) the Scholarship of Application, (2) the Scholarship of Discovery, (3) the Scholarship of Integration, and (4) the Scholarship of Teaching. Graduate students must experience these components of an integrated whole to learn to engage disparate colleagues, face an increasing range of challenges and expectations, and assume ever-changing career roles (pp. 52-53).

InSight: A Journal of Scholarly Teaching 
While research affirms the responsibility of departments and universities to prepare TAs for their roles as instructors-in no small part to support effective educational experiences for undergraduates-university recognition and financial support continue to reward research rather than teaching (Austin \& McDaniels, 2006b; Nyquist, et al., 1999; Prieto, 2002; University of Texas at Austin, 2007). Even as universities provide programs that validate TA training, i.e., they acknowledge the importance of training, they neglect to provide structures that legitimize such training, i.e., they fail to provide institutional documentation or recognition of teacher training. Unlike a graduate student's research training, which is legitimized through grant funding, research awards, and notation on their transcripts, there are relatively fewer mechanisms through which the pedagogical training that will be crucial to many graduate students' success as future faculty is similarly legitimized.

So, the task for those who support TA's is not to de-emphasize research or other aspects of scholarship but rather to ensure that teaching and teacher training are appropriately appreciated as essential for TA's to develop the self-efficacy, socialization, and competencies requisite for success in the classroom. In short, universities are responsible for preparing graduate students for their roles as future faculty, and part of this preparation, i.e., their preparation as teachers, has yet to be legitimized at the institutional level in many universities. Research-oriented contributions to their academic discipline receive legitimization through entries on official university transcripts, presentations at academic conferences, and publications associated with their research. We argue here that universities are responsible for providing similar legitimizing mechanisms to highlight TAs' contributions to undergraduate learning and their own pedagogical development. We will demonstrate that, although TA's and universities validate graduate student teacher training and graduate students attempt to provide their own legitimization for this type of training, universities do relatively little to institutionally legitimize TA pedagogical development.

\section{Institutional Level Validation of Pedagogical Development: A Case Study}

In this section, we present a case study that illustrates how a successful TA training program at The University of Texas at Austin (UT Austin) validates graduate student pedagogical development at the institutional level but does not take the next step and legitimize the training. Fundamentally, the existence and continued funding of the Graduate Student Instructor (GSI) Program demonstrate institutional-level validation by the university. The remainder of this section will show how the skills developed through the GSI Program, while focused on teaching, are similar to the research skills developed through departmental offerings. As we will demonstrate, the same skills, framed as critical to research, are institutionally legitimized, whereas a graduate student's pedagogical preparation is not.

The GSI Program includes five components: (1) Promising Practices, an online repository of TA-submitted best practices; (2) the GSI Colloquium, an annual teaching and learning conference; (3) ASPECTS (Advancing Students' Professional Excellence with Certificates in Teaching Series), a free pedagogy and professional development workshop series; (4) support workshops for requisite departmental pedagogy courses; and (5) individual consulting sessions. Each component addresses critical institutional needs to

But whereas participation in research-oriented collaborative networks is legitimized through professional conferences, co-authored journal articles, and grant-funded multiinstitutional or interdisciplinary projects, participation in pedagogyfocused collaboration is seldom legitimized as a valid pursuit for future scholars. 
incorporate validated and legitimized preparation in academic skills to develop graduate students as whole scholars.

Promising Practices provides a venue for experienced TAs to share teaching insights with peers. The venue normalizes pedagogy-oriented communications, and it responds, albeit indirectly, to Austin and McDaniels' call for 'informal conversations" with faculty to encourage scholarly development (2006b, p. 60). Although the TA conversations are not with faculty per se, they nonetheless occur among teaching peers-some with more experience than others.

Just as it is critical that researchers learn to work with others to identify challenges and to develop collective strategies to overcoming challenges, Promising Practices helps TA's develop similar sorts of collaborations that focus on identifying classroom-centered challenges and responses. But whereas participation in research-oriented collaborative networks is legitimized through professional conferences, co-authored journal articles, and grant-funded multi-institutional or interdisciplinary projects, participation in pedagogy-focused collaboration is seldom legitimized as a valid pursuit for future faculty.

The GSI Colloquium offers a larger, real-time, face-to-face venue for such exchange, with interactive teaching presentations led by peers from across campus. The colloquium also provides an opportunity for TAs to learn from teaching support staff in mandatory consultations that ensure the inclusion of an interactive component and optimization of cross-discipline applicability.

Colloquia and conferences provide opportunities for graduate students to develop professional networks, learn from their peers, and receive feedback on presentations about their experiences. Yet, while university grants for graduate students may be based partially on their research activity at conferences, little funding is earmarked to reward graduate students for participating in pedagogicallyoriented conferences such as the GSI Colloquium, where they are developing similar professional skills.

ASPECTS pedagogy workshops address topics such as designing effective lectures and leading discussions, offering TA's the opportunity to earn certificates that are not, however, recorded on official transcripts. To earn certificates, TA's must demonstrate that they have thought deeply about how session concepts relate to current or future teaching, and then submit an essay that incorporates key workshop principles into a course design or lesson plan.

Graduate students attend the pedagogy workshops voluntarily, seeking professional development opportunities in current pedagogical theory and practice. Similar workshops focused on research practice-summer institutes or study abroad programs-provide opportunities to work with specialists. Work with research specialists (e.g., extra-departmental statisticians or information scientists) improves a TA's research, which consequently situates them better to receive institutional recognition. The same recognition does not exist to reward TA's for their engagement with pedagogy specialists, which improves their teaching.

Support workshops for requisite departmental pedagogy courses mirror, in many ways, the pedagogy-focused workshops. Prior to appointment, every prospective teaching assistant at UT Austin must enroll in a three credit hour pedagogy course, "Supervised Teaching," taught by departmental faculty-another example of efforts by the university to validate pedagogical development. The supervising faculty frequently request that GSI Program staff present workshops during class meetings. Unlike the free workshops, the support workshops occur in conjunction with the discipline-specific training that Luo, Bellows, and Grady (2000, p. 374) believe is critical to acquiring disciplinary norms and practices. The discipline-specific focus of this model responds to the call for overt discussions of the value of teaching in academia (Park, 2004; Prieto, 2002; Austin \& McDaniels, 2006b; Nyquist, et al., 1999).

While these for-credit courses provide an example of institutional legitimization-they actually appear on a transcript-they may nevertheless serve to devalue pedagogical training. The inference one may draw is that a single pedagogy course that may simply meet for three hours a week during one semester is enough

InSight: A J ournal of Scholarly Teaching 
for one to become an effective teacher. Developing effective teaching practices is an iterative, reciprocal, and reflective process that occurs over the course of many years throughout one's classroom experiences. To truly legitimize all such pedagogy training, transcripts should reflect successful engagement in all of the institutionally sponsored opportunities.

Individual consultations provide TA's with services tailored to specific classroom concerns. Through individual consultations, graduate students develop many of the skills necessary to be both effective instructors and competent members of the academic research community. Leading researchers do not work in isolation; they receive feedback from journal editors, peers, and colleagues. Similarly, graduate students who participate in individual consultation learn from personalized feedback on their teaching, and they develop strategies for improvement. To pass a class or to write a dissertation, graduate students must be able to solicit, receive, and respond to feedback. The university and academic departments expect graduate students to respond to feedback related to their learning or research, which is indicated by passing grades on a transcript or through earning a university-validated degree. However, typically missing from a transcript is similar proof of their response to teaching-oriented feedback.

Our goal in this section was to demonstrate that pedagogical training for TA's is not legitimized at the institutional level when similar skills are legitimized when framed as critical to research. We turn next to a discussion of how this pedagogical training is, however, validated at both the individual and institutional levels.

\section{Validation of Pedagogical Development by Graduate Students}

Continued funding of the GSI Program suggests that UT Austin believes the pedagogical development of graduate students is important. In this section, we provide evidence that graduate students themselves understand the importance of their pedagogical development. If they did not value or validate their own pedagogical development, then the lack of institutional legitimization might be justified. However, by demonstrating that graduate students are becoming increasingly engaged with the GSI Program and are satisfied with the training, we show that they perceive pedagogical development as a valid endeavor. To this end, we have employed three metrics to demonstrate the validity of pedagogical training from the graduate student's perspective: (1) instructional effectiveness, (2) program viability, and (3) program growth.

The first metric is based on participant feedback about the quality and effectiveness of the instruction provided by each program interaction. After every interaction, GSIs respond to survey items designed to gauge whether they found their experiences to be valuable. For the period from fall 2004 to fall 2009, the average participant response to all items was 4.5 on a 5-point scale, indicating that they found their experiences "extremely valuable." Qualitative data provided by participants indicate that the strategies and techniques they experienced during their interaction with the GSI Program made them better instructors. These responses to the evaluations allow for students to provide feedback on single offerings, but provide relatively little insight for gauging whether students consider their overall pedagogical development to be valuable. High evaluation scores may be associated with a skilled instructor or with a coincidentally relevant or timely session. Measures of instructional effectiveness are insufficient by themselves for understanding whether TA's validate their own pedagogical development.

By assessing program viability, we find that a more nuanced understanding of the value that TA's place on their development as teachers emerges. We judge program viability based on whether participants indicate at the conclusion of a given interaction that they plan to have future interactions with the GSI Program. Participants who indicate that they will attend a future offering imply that they engaged in a valid learning experience, since no institutional credit or honors are 
awarded for their participation. Since teaching assistantships are not awarded based on attendance at GSI Program offerings or on demonstrated teaching competence (e.g., through end-of-semester evaluations), TA's have little extrinsic motivation to attend. While participation in pedagogical development activities may curry a particular supervisor's favor, there are no official mechanisms that translate this favor into tangible outcomes, e.g., higher consideration for TA appointments or increases in pay based on classroom performance. Rather, TA's note that their attendance is intrinsically motivated by their desire to become better teachers, which they realize is crucial for job placement and success as future faculty. Put simply, regardless of the quality of an offering, if participants do not find the experience valuable, there is no motivation to attend future offerings.

Based on data collected from 2004 through 2009, Figure 1 shows that over time, TA's who have had initial interactions with the GSI Program indicate that they plan to attend GSI Program offerings in the future. In 2004, 32\% of participants indicated that they would attend a future offering. By 2009, this figure grew to $96 \%$. This finding suggests that, from 2004 to 2009, participants increasingly found pedagogical development to be a valuable endeavor, which suggests that more participants at UT Austin began validating pedagogical development. This pattern in viability data can help in interpreting the growth data presented below.

Figure 1: Percentage of GSI Program Participants Indicating Plans to Attend Future Offerings ( 2004 through 2009)

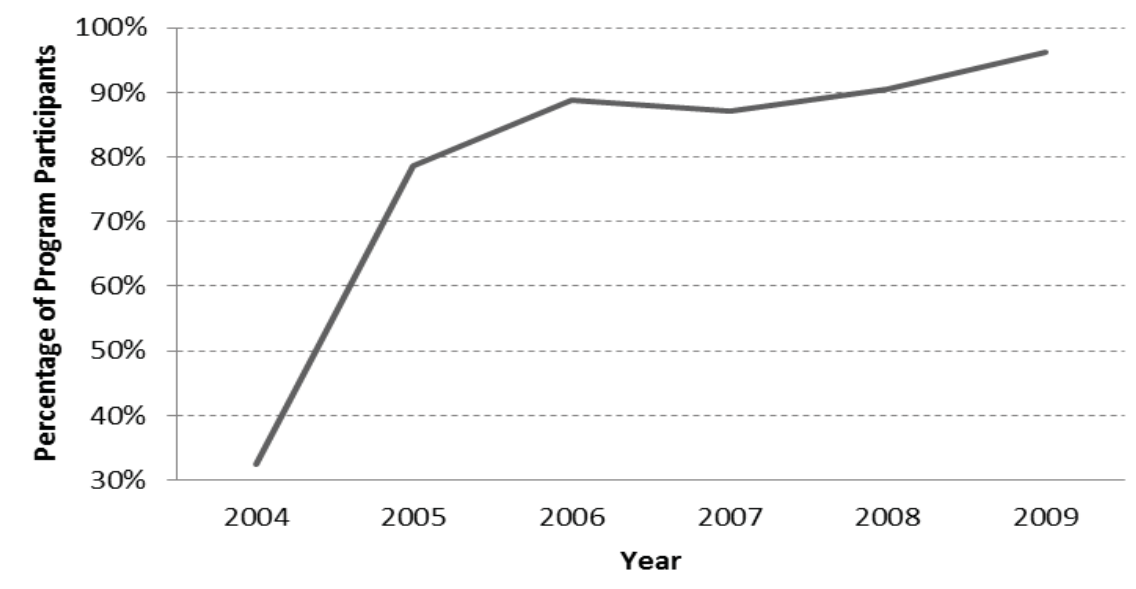

The data presented in Figure 1 for program viability shows that individual TA's have increasingly found their pedagogical development to be valuable as they progressed through their graduate programs. Like program viability, program growth provides insights into whether TA's from across the university validate their own pedagogical development. The data in Figure 2 shows that the total number of unique attendees has increased over the lifespan of the program. The GSI Program has served 3,204 unique TAs from 2004 through 2009. At its inception in 2004, the program served 137 unique TA's, while in 2009 the program served 853 unique TAs, nearly an $800 \%$ increase. Since participants attend an average of almost two sessions, it is clear that many are engaging the program repeatedly, which may imply that the workshops and colloquia are sufficiently diverse and are perceived as meeting a wide range of participants' future faculty needs. 
Figure 2: Number of Unique Attendees at GSI Program Offerings (2004 through 2009)

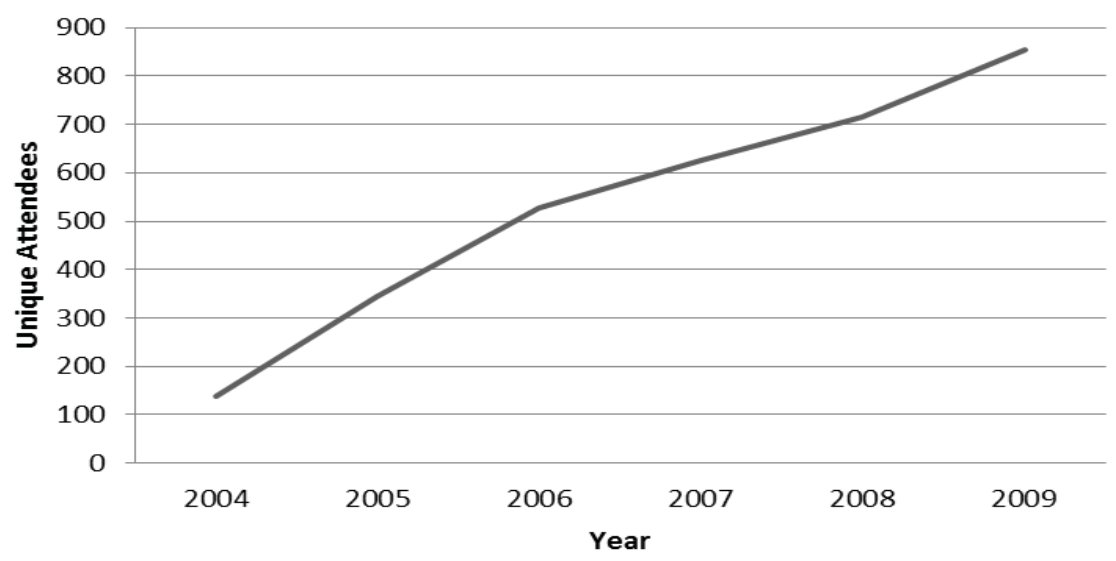

The summary of evaluative data presented above suggests that graduate students are satisfied with the program's offerings and that graduate students from across campus are increasingly interested in seeking opportunities for pedagogical development. The increased interest and attendance over the lifespan of the program indicate that graduate students see the value in developing the skills necessary for success in the classroom.

Moreover, academic departments increasingly see the value in engaging extra-departmental teacher-training staff to ensure that their undergraduate students are being led by TA's versed in contemporary, research-based best practices in teaching and learning. Departments are increasingly leveraging the specialized knowledge imparted by GSI Program staff to complement existing pedagogy training. Additionally, the GSI Program has seen an increase in and a routinization of requests for support workshops to complement departmental pedagogy courses.

For some of these courses, pedagogical development is being further validated by course policies that require graduate students to attend GSI Program workshops in addition to their normal course load. In these cases, the validation of a graduate student's pedagogical development has percolated to the departmental level, as departments are increasingly incorporating GSI Program offerings in their for-credit pedagogy courses. The GSI Program supports such bottom-up approaches to legitimizing graduate student pedagogical development, as graduate students who voluntarily attend program offerings relate their positive learning experiences to their faculty supervisors, who in turn may require attendance at offerings for a passing grade in the for-credit course.

\section{Graduate Student Desire for I nstitutional Legitimization of Teacher Training}

Their willing pursuit of teacher training demonstrates that graduate students understand that success in the classroom is tied to success in the academic job market. And although institutions are solely responsible for granting legitimacy to a given practice, TA's have developed innovative ways to take responsibility for legitimizing their own pedagogical development.

1. Ad hoc teaching portfolios: Many TA's purchase private web space and create online documentation of materials that they produced while interacting with the GSI Program. Such unofficial teaching portfolios serve to collect and organize the evidence that students are 
competent, effective instructors. The portfolios may contain teaching videos recorded during individual consultation, syllabi created during a workshop, or slides presented at the GSI Colloquium.

2. Requests for Letters of Recommendation from GSI Staff: Often, GSI staff work more closely with TA's on their pedagogical development than do departmental faculty, so TA's may seek recommendation letters from GSI staff when applying for faculty positions. These recommendations document and legitimize the skills and talents that TAs have developed over their academic careers.

3. Inclusion of ASPECTS Certificates on Resumes: Many TA's who earn ASPECTS certificates note them on their curricula vitae to highlight their commitment to pedagogical development. Official, institutionally certified documentation would serve to strengthen the legitimacy of this commitment.

Despite the lack of institutional legitimization for graduate student teacher training, TA's have developed creative ways to highlight the value that they place on their development as effective teachers. However, institutions must do more to support these legitimization practices by TA's.

\section{Towards Institutional Legitimization of Teaching at the University}

We contend that (1) through the services provided by the GSI Program, the university believes that teacher training for TA's is a valid endeavor; (2) based on the success of the GSI Program, TA's value their own training as teachers; and (3) TAs are engaged in unofficial practices that demonstrate their desire for institutional legitimization of their pedagogical development. However, legitimization of pedagogical development remains within the purview of the institution. Just as the university legitimizes academic performance by means of transcripts and funding bodies legitimize research by means of grants, we argue that the university has the responsibility to legitimize graduate student pedagogical development in similar, officially documented ways.

Although the university appears committed to preparing graduate students for their future scholarly roles of both teacher and researcher, only the role of researcher is currently emphasized. The next step is legitimizing the graduate student's growth as teacher and researcher-that is, a whole or complete scholar. To take this step toward institutional legitimization, we offer three recommendations:

1. Integrate for-credit, university-mandated departmental pedagogy courses with support programs staffed by teaching and learning specialists. This model will ensure that discipline-specific content is coupled with current best practices in teaching and learning, while students will be awarded credit towards graduation, narrowing the gap between the importance of research and teaching in a graduate student's evolution to future faculty.

2. Create a university-supported e-portfolio system to encourage the cultivation and dissemination of best teaching practices. These professional development products will serve not only to market individuals to prospective institutions but also to market the university to new undergraduates, graduate students, and faculty.

3. At the minimum, pedagogy-oriented professional development efforts undertaken by graduate students should be recognized with transcript notation.

By considering these recommendations, universities can ensure that the pedagogical training that is validated at multiple levels (individual and departmental) can become institutionalized. By offering legitimacy for teacher 
training, universities could concretely demonstrate a commitment to ensuring a quality education for all students, thus better preparing them for futures both inside and outside of the academy.

\section{References}

Austin, A. E., \& McDaniels, M. (2006a). Preparing the professoriate of the future: Graduate student socialization for faculty roles. In J. C. Smart (Ed.), Higher education: Handbook of theory and research, (pp. 397-456). Dordrecht, Netherlands: Springer.

Austin, A. E., \& McDaniels, M. (2006b). Using doctoral education to prepare faculty of work within Boyer's four domains of scholarship. New Directions for Institutional Research, 129, 51-65.

Branstetter, S. A., \& Handelsman, M. M. (2000). Ethical beliefs, behaviors, and training of graduate teaching assistants. Ethics and Behavior, 10(1), 27-50.

Benassi, V. A., \& Fernald, P. S. (1993). Preparing tomorrow's psychologists for careers in academe. Teaching of Psychology, 20, 149-155.

Cahn, S. M. (1994). Saints and scamps: Ethics in academia. Lanham, MD: Rowman \& Littlefield.

Darling, A. L., \& Dewey, M. L. (1990). Teaching assistant socialization: Communication with peer leaders about teaching and learning. Teaching and Teacher Education, 6, 315-326.

Golde, C. M., and Dore, T.M. (2001). At cross purposes: What the experiences of doctoral students reveal about doctoral education. A report prepared for The Pew Charitable Trusts. Retrieved from http://www. phd-survey.org

Graft, J. G., \& Lambert, L. M.. (1996). Socializing future faculty to the values of undergraduate education. Change, 28, 38-46.
Kuther, T. L. (2002). Ethical conflicts in the teaching assignments of graduate students. Ethics and Behavior, 12, 197-204.

Kuther, T. L. (2003). Teaching the teacher: Ethical issues in graduate student teaching. College Student Journal, 37, 219-224.

Lowman, J., \& Mathie, V. A. (1993). What should teaching assistants know about teaching? Teaching of Psychology, 20, 84-89.

Luo, J., Bellows, L., \& Grady, M. (2000). Classroom management issues for teaching assistants. Research in Higher Education, 41, 353-380.

Meyers, S. A., \& Prieto, L. R. (2000). Training in the teaching of psychology: What is done and examining the differences. Teaching of Psychology, 27, 258-261.

Nyquist, J., Manning, L., Wulff, D. H., Austin, A. E., Sprague, J., Fraser, P. K., Calcagno, C., \& Woodford, B. (1999). On the road to becoming a professor: The graduate student experience. Change, 18-27.

Park, C. (2004). The graduate teaching assistant (GTA): Lessons from North American experience. Teaching in Higher Education, 9, 349361.

Prieto, L. R. (2002). Teaching assistant development: Research and impressions. In W. Buskist, V. Hevern, \& G. W. Hill, IV (Eds.), Essays from e-xcellence in teaching, 2002. Retrieved from http://teachpsych.org/resources/ebooks/e-books.php

Prieto, L. R., \& Altmaier, E. M. (1994). The relationship of prior training and previous teaching experience to self-efficacy among 
graduate teaching assistants.

Research in Higher Education, 35, 481-497.

Prieto, L. R., \& Meyers, S. A. (1999). The effects of training and supervision on the self-efficacy of psychology graduate teaching assistants. Teaching of Psychology, 26, 264-266.

Smallwood, S. (2001). Survey points to mismatch in doctoral programs. Chronicle of Higher Education, 47, A14.

University of Texas at Austin, (2007). Strauss Center creates Jon Brumley Chair in global affairs; \$1 Million gift to fund research on benefits, dangers of technology. News from the Office of Public Affairs, Retrieved from http://www.utexas. edu/news/2007/1 1/05/strauss-2/

Josh Iorio is a post-doctoral research scientist in the Project Network Dynamics Lab at Columbia University. He has a PhD in Sociolingusitics from the University of Texas at Austin, where he worked for 4 years in the Division of Instructional Innovation and Assessment (DIIA). During his time with DIIA, Dr. Iorio worked with graduate students to develop strategies for enhancing their teaching effectiveness. He currently works with faculty in Engineering, Architecture, and Construction at Columbia to develop rubrics for classroom-based research projects. His current research explores how virtual worlds can be used to integrate faculty research and teaching in Science, Technology, Engineering, and Mathematics (STEM) disciplines.

Mark Decker is a doctoral candidate in Education Psychology-Cognition, Learning, Motivation and Instruction-at the University of Texas at Austin. He also holds a Master of Science in Social Work degree with an emphasis in administration and planning from the University of Texas and was the coordinator of the Graduate Student Instructor Program since its inception in 2004 until the fall of 2010. Prior to joining the GSI Program, Mr. Decker headed the Center for Instructional Technologies' Courseware Group which provided university-wide training, support and consulting for Web course development tools-WebCT, and then Blackboard from 2000 until 2004.

InSight: A J ournal of Scholarly Teaching 